\title{
The relationship between EFL learners' self-efficacy and their social-affective strategy use across years of study
}

Mojtabaee Hosseini, Seyyedeh Mehrnaz

University of Guilan, University Campus 2, Iran (mehrnazhosseini70@yahoo.com)

Tahriri, Abdorreza $\$

University of Guilan, Iran (atahriri@gmail.com)

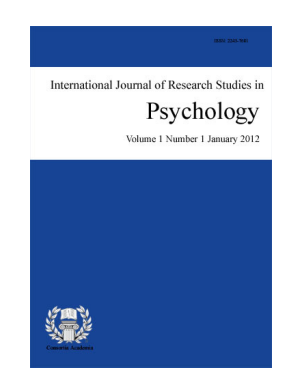

Danaye Tous, Maryam

ISSN: 2243-7681 Online ISSN: 2243-769X

University of Guilan, Iran (Maryam.dana@gmail.com)

OPEN ACCESS

\section{Abstract}

The present study investigated the relationship between self-efficacy and social-affective strategy use of EFL learners across years of study. To this end, 170 male and female undergraduate students were selected through convenience sampling. The instruments included Self-Efficacy for Learning Form (SELF-A) and the social-affective section of the Strategy Inventory for Language Learning (SILL). Chi-square test and Spearman rank-order correlation were run to examine the relationship between the variables. The result indicated that there was no relationship between self-efficacy and year of study. Moreover, no relationship was found between the participants' social-affective strategy use and year of study. However, there was a significant positive relationship between self-efficacy and social-affective strategy across third and fourth years of study.

Keywords: self-efficacy; social-affective strategies; year of study; EFL 


\section{The relationship between EFL learners' self-efficacy and their social-affective strategy use across years of study}

\section{Introduction}

Learners as the central part of language acquisition have individual differences, which affect learning and the way that they pick up language tasks. In this way, teachers should identify the specific ways and actions that successful learners employ in language learning and teach them to other students as to help all learners achieve their goals. According to Oxford (1990), these specific actions are called language learning strategies. Oxford (1990) defined language learning strategies as "specific actions taken by the learner to make learning easier, faster, more enjoyable, more self-directed, more effective, and more transferable to new situations" (p. 98). She divided language learning strategies into two main categories, direct and indirect strategies which are further subdivided into six classes. Social and affective strategies that are part of the indirect strategies are the focus of this study. As Oxford and Nyikos (1989) argued, "unlike most other characteristics of learners, personality and general cognitive style, learning strategies are readily teachable" (p. 291). Strategies enable learners to find the best way to perform a task. O’Malley, Chamot, Stewner-Manzanares, Russo, and Kupper (1985) stated that learning strategies of proficient language learners applied to less proficient learners could have useful effects on facilitating the development of learning foreign language skills. However, just identifying and teaching these strategies are not sufficient to have high efficiency in language learning.

Self-efficacy "is a psychological concept which encompasses individualistic adaptive capabilities. It refers to peculiar ways by which people act in various situations which depends on the reciprocity of behavioral, environmental and cognitive conditions" (Datu, 2013, p. 4). In fact, learners should trust in their own ability to successfully learn and perform the desired action. Self-efficacy, as defined by Bandura (1977), refers to this belief. Belief is even more important than people's ability which makes people capable of predicting the outcome and results of their actions (Zimmerman, 2000) and either motivates or demotivates them in their course of action (Schunk \& Gunn, 1986). A good prediction causes a strong sense of motivation toward doing required actions but prediction of failure can prevent them from continuing their jobs (Schwarzer, 1992; Zimmerman, 2000).

Concerning the significance of the study, it is to be stated that, in the last past two decades, attention has been shifted toward learners' variables in foreign language acquisition and in this regard self-efficacy has been studied and it was found that learners' self-efficacy beliefs strongly affect their performance (Bandura, 1997). In academic fields, self-efficacy was found as a strong predictor of academic performance (Pajares \& Kranzler, 1995).

This study will signify the paramount role of social-affective strategies in EFL context. In previous studies in which self-efficacy has been investigated in relation to language learning strategies, cognitive and metacognitive strategies were highlighted as some factors more relevant to self-efficacy and the relationship between these two variables were considered across proficiency levels (Bonyadi, Rimani Nikou, \& Shahbaz, 2012; Ghavamnia, Kassaian, \& Dabaghi, 2011; Purdie \& Oliver, 1999). In particular, this study tries to investigate the relationship between self-efficacy and social-affective strategy use across years of study.

\section{Review of Related Literature}

\subsection{Effects of self-efficacy on human functioning}

Self-efficacy affects human functioning through four major processes including cognitive, motivational, 
affective and selection processes (Bandura, 1994). Through cognitive processing, self-efficacy affects the function of thought. In other words, when people are faced with difficult tasks, they need to develop a sense of confidence and success over the situation before performing the necessary action. In this regard, low self-efficacious people become confused in their analytic thinking and the quality of their performance will be diminished. In contrast, high self-efficacious ones make best use of their analytic thinking and set themselves challenging goals which improve their quality of performance (Wood \& Bandura, 1989). Motivational processing is closely related to the cognitive processing, since it is human thought which can form their motivation (Bandura, 1994). People can't motivate themselves if they are not able to anticipate success in their future action. As Bandura says, "efficacy beliefs play a key role in the self-regulation of motivation" (p. 11). People, based on their beliefs about their capabilities, predict the outcome of action and motivate themselves to set the required effort to achieve that outcome.

Affective process is the third level: Peoples' efficacy beliefs determine the amount of stress and motivation which people have in difficult and challenging situations (Bandura, 1989, p. 1177). The more people believe in their capabilities to control a difficult situation, the level of stress and anxiety will be reduced; otherwise, the amount of anxiety will be increased and their attention will be directed toward what will happen (Bandura, 1997). It is where people's belief directly affects their functioning (Lazarus \& Folkman, 1987; cited in Zajacova, Lynch, $\&$ Espenshade, 2005). Selection process is the last one; another important effect of self-efficacy belief on human functioning is on the activities and situations that people select. People typically select those activities and situations that are matched to their capabilities in their own beliefs and do not spend their time on the activities and situations which is beyond their capabilities.

\subsection{Effects of self-efficacy on academic achievement}

A look at the literature shows us that self-efficacy contributes to academic achievement. It can be inferred from Bandura and Schunk (1981) and Pajares (2002) that self-efficacy influences the choice of task and activity that learners pick up, the effort they exert and their final achievement. According to Bandura (1986), people tend to avoid situations and activities which they believe exceed their capacities, but they are willing to undertake and perform those tasks or activities which they consider themselves to be capable of accomplishing successfully. So it affects the choice of task (Zimmerman, 2000). The amount of effort will be increased or decreased to the extent that they believe it can lead to better achievement (Bandura, 1986) and the goal that they set for themselves is the one which fits their beliefs. Learners with a high level of self-efficacy set greater and challenging goals and those with low level of self-efficacy set smaller goals. The more challenging the goals are, the more motivation they stimulate (Locke \& Latham, 1990).

In a study by Goulão (2014), the relationship between self-efficacy and academic achievement was conducted on adult learners considering their gender. Data were collected from 63 male and female students whose age ranged from 25 to 60 and were in the first years of their undergraduate studies. The MSLQ questionnaire was used as the data-elicitation instrument. Descriptive and inferential statistics were used to analyze the data and it showed a high level of self-efficacy for students and a significant relationship between the self-efficacy of the students and their academic performance. It has been further found that there is no correlation between gender and self-efficacy.

In a study carried out in Ethiopia, Tenaw (2013) managed a study on Analytical Chemistry students to explore whether self-efficacy improves learners' achievement in this area and also whether there is a gender difference in this relationship. He randomly selected 110 students out of which 100 individuals remained in the study. In order to collect the data, a self-efficacy scale, students' achievement test consisting of analytical chemistry questions and students' focus group discussion with four open-ended questions were administered. The data were analyzed and the results revealed no significant difference in the participants' self-efficacy regarding gender; however, it showed a significant difference in their academic achievement across gender and also a positive relationship between self-efficacy and academic achievement. 


\subsection{Classification of language learning strategies}

The most inclusive taxonomy of language learning strategies was provided by Oxford (1990). Oxford divided language learning strategies into two main categories, direct and indirect strategies which are also subdivided into six classes. Direct strategies are further sub-divided into memory, cognitive and compensation strategies. Indirect strategies do not directly involve using the language but provide indirect support for language learning by employing different strategies such as focusing, arranging, evaluating, seeking opportunities, and lowering anxiety. Indirect strategies include metacognitive, affective and social strategies. Social and affective strategies are the focus of this research.

Affective strategies, as its name shows, deal with emotional and affective states and assist students to manage their emotions, motivation, and attitudes associated with learning. They can be achieved through lowering anxiety, encouraging oneself, and taking emotional temperature. Social strategies facilitate language learning through interactions with others. Language is a form of social behavior and learning it involves other people, and it is extremely important that learners employ appropriate social strategies in this process (Oxford, 1990). These strategies are divided into three sets, namely, asking questions, cooperating, and empathizing with others.

There are a number of studies which show a positive relationship between self-efficacy and language learning strategies. Bonyadi, Rimani Nikou, and Shahbaz (2012), in a study on the relationship between EFL learner's self-efficacy and language learning strategy use, selected 130 male and female students of three universities as the participants. Using the Persian Adaptation of General Self-efficacy Scale and Strategy Inventory for Language Learning questionnaires, they found a positive relationship between self-efficacy and only metacognitive strategies. Ghavamnia, Kassaian, and Dabaghi (2011), working on 80 female students of Isfahan university and with administering SILL questionnaire and BALLI, similarly found a positive relationship between these two variables. Purdie and Oliver (1999), with 58 bilingual primary school-aged children, examined the relationship between these variables and found the same result.

As for the present study, the first purpose was to investigate the relationship between EFL learners' self-efficacy across years of study. Another purpose was to explore the relationship between EFL learners' use of social-affective strategies and their years of study. More importantly, its purpose was to find if there was a relationship between self-efficacy and social-affective strategy use across years of study. As such, this study sought to answer the following questions:

$>$ Are there statistically significant relationships between EFL learners' self-efficacy and their years of study?

$>$ Are there statistically significant relationships between EFL learners' use of social-affective strategies and their years of study?

$>$ Is there a statistically significant relationship between EFL learners' self-efficacy and their use of social-affective strategies across years of study?

In line with the above-research questions, the following null hypotheses will be tested:

$>\quad H_{0}$ : There are not statistically significant relationships between EFL learners' self-efficacy and their years of study.

$>\quad H_{0}$ : There are not statistically significant relationships between EFL learners' use of social-affective strategies and their years of study.

$>\quad H_{0}$ : There is no statistically significant relationship between EFL learners' self-efficacy and their use of social-affective strategies across years of study. 


\section{Methodology}

To answer the research questions, a survey study of cross-sectional type was conducted. To this end, a group of EFL learners from four years of study including freshmen, sophomores, juniors, and seniors were selected to take part in the study.

\subsection{Participants}

The participants of this study were $170 \mathrm{EFL}$ male and female undergraduate students at University of Guilan, Rasht, Iran majoring in English Language and Literature. They were selected based on convenience sampling. Persian was the first language of the participants and their age ranged between 18 and 34 with the mean age of 19.8 and they were selected from four different years of study. In this study, academic year of participants was the criterion for selection. Fifty-five participants were first-year, 40 of them were second-year, 37 were third-year and 38 were fourth-year students.

\subsection{Instruments}

The data collection instruments of this study are as follows:

Strategy Inventory for Language Learning (SILL) - Strategy Inventory for Language Learning (SILL) is used for researching about the frequency of learners' use of 50 common strategies. It consists of five sections in which the learners are asked to report on a scale of one to five how often they use each strategy. The structure of SILL is based on Oxford's classification system, whereby strategies are grouped into six categories, each represented by a number of individual strategies: Memory strategies (items 1-9); Cognitive strategies (items 10-23); Compensatory strategies (items 24-29); Metacognitive strategies (items 30-38); Affective strategies (items 39-44) and Social strategies (items 45-50). In the present study, the last two categories were used to elicit the data. As the existing literature reveals, the SILL seems to be the only language learning strategy instrument that has been checked for reliability and validated in multiple ways (Oxford \& Burry-Stock, 1995). Mohammadi and Alizadeh (2014) in a study examined the reliability and validity of SILL for use among Iranian university students. Findings from the study revealed that the SILL score of test-retest was reliable with excellent reliability (Pearson's correlation $>$.8). Exploratory and confirmatory factor analyses were run on the SILL to investigate construct validity. Demirel (2009), in his study examining the adaptation of strategy inventory for language learning into Turkish, found a correlation coefficient of .92 and test-retest reliability coefficient of .83 .

Self-Efficacy for Learning Form (Self-A) - SELF-A is an abridged version of the SELF (Self-Efficacy for Learning Form) which has been developed by Zimmerman and Kitsantas (2007) to measure academic self-efficacy. SELF consists of a 57-item survey designed to measure perceived efficacy with regard to reading, note taking, test-taking, writing, and studying which assess a wider variety of domains whereas the SELF-A consists of 19 of the original 57 items that measure a specific type of academic self-efficacy known as the ability to self-regulate learning (SRL). The 19 items focused on three specific academic tasks: studying, test-preparation and note-taking. Six of the 19 items assessed academic self-efficacy beliefs regarding studying, six assessed beliefs about note-taking skills, and seven assessed confidence in test preparation skills. Items dealing with reading and writing included in the unabridged version were not included in the abridged version as "they were viewed as more limited in scope of application than other processes" (Zimmerman \& Kitsantas, 2007, p. 159). Due to the focus of this study on academic self-efficacy, SELF-A questionnaire was preferred to be used. In order to remove the possible misunderstanding of the participants, the translated forms of both questionnaires were used.

\subsection{Procedure}

Prior to the main phase of the study, a pilot study was initially carried out with 35 participants similar to the target group, to assess the reliability of the instruments and make sure that the procedures are appropriate. To this 
Mojtabaee Hosseini, S. M., Tahriri, A., \& Danaye Tous, M.

end, Cronbach's alpha was used and the reliability of the two instruments was calculated. The alpha reliability of both instruments was .76 which shows the high reliability of the instruments.

After the permission was obtained to conduct the study at the university under study and the participants were ensured about the confidentiality of their responses, the data collection started in the spring term of 2015 . The participants were first informed about the purpose of the study and were ensured about their anonymity as well. Both questionnaires were administered in one session in every class. SILL (social and affective categories) was conducted to know about the extent that participants make use of social-affective strategies. The required time for completing it was about 15 minutes. The next questionnaire which is SELF-A Questionnaire was administered to test the participants' degree of academic-self-efficacy. They were given 10 minutes to complete this questionnaire. The data were gathered in the class hour. After the data were collected, they were subjected to statistical analysis.

Descriptive statistics including means and standard deviations were computed for the data obtained from the self-efficacy and SILL questionnaires. Then, two Chi-square tests were run to answer the first and second research questions. Finally, Spearman rank-order correlation was run to examine the relationship between EFL learners' self-efficacy and their use of social-affective strategies across years of study.

\section{Results}

\subsection{Descriptive statistics for the self-efficacy and strategy use questionnaire}

Table 1 presents the results of descriptive statistics:

\section{Table 1}

Descriptive statistics for the EFL students' self-efficacy beliefs and social-affective strategy use

\begin{tabular}{llcccc}
\hline Years of study & & Self-efficacy & $\begin{array}{c}\text { Affective } \\
\text { strategies }\end{array}$ & $\begin{array}{c}\text { Social } \\
\text { strategies }\end{array}$ & $\begin{array}{c}\text { Social-affective } \\
\text { strategies }\end{array}$ \\
\hline First year & $\mathrm{N}$ & 55 & 55 & 55 & 55 \\
& Mean & 60.5904 & 2.8939 & 3.2182 & 3.0561 \\
& Std. Deviation & 13.10482 & .61058 & .72142 & .57848 \\
& Sum & 3332.47 & 159.17 & 177.00 & 168.08 \\
\hline Second year & $\mathrm{N}$ & 40 & 40 & 40 & 40 \\
& Mean & 64.8947 & 2.8292 & 2.9125 & 2.8708 \\
& Std. Deviation & 10.06069 & .64327 & .80595 & .58255 \\
Third year & Sum & 2595.79 & 113.17 & 116.50 & 114.83 \\
& $\mathrm{~N}$ & 37 & 37 & 37 & 37 \\
& Mean & 67.5676 & 3.2027 & 3.1171 & 3.1599 \\
\hline Fourth year & Std. Deviation & 14.12273 & .68846 & .72634 & .63172 \\
& Sum & 2500.00 & 118.50 & 115.33 & 116.92 \\
\hline & $\mathrm{N}$ & 38 & 38 & 38 & 38 \\
& Mean & 64.7645 & 3.1974 & 3.0219 & 3.1096 \\
& Std. Deviation & 11.99682 & .91522 & .78286 & .69374 \\
& Sum & 2461.05 & 121.50 & 114.83 & 118.17 \\
\hline
\end{tabular}

Table 1 shows the means and standard deviation for the EFL learners' level of self-efficacy beliefs. As it can be seen, the average level of first-year students' self-efficacy beliefs was 60.59, implying the fact that the participants felt relatively moderate of their capabilities to organize and execute courses of action required to attain designated types of performance. On the scale, a value of (6) indicated, "feel that $60 \%$ I 'can do it'." Similarly, the average level of second-year students' self-efficacy was 64.89 suggesting that the second-year students expressed relatively moderate confidence in their ability to perform the behavior required to produce specific outcomes. However, the average level of third-year students' self-efficacy was 67.56. This indicated that 
the third-year students felt that they probably could do it. In fact, third-year students reflected higher positive belief in their capabilities to carry out, organize and perform a task successfully. For the fourth-year students, the mean value of self-efficacy amounted to 64.76 again, implying relatively moderate judgments of their capabilities.

Table 1 also shows the degree of employed social affective strategies by the EFL learners. As it is shown, the affective strategy use of the third and fourth year students $\left(M_{\text {third year }}=3.20 ; \mathrm{M}_{\text {fourth year }}=3.19\right)$ was considerably higher than that of the first- and second-year students' use of affective strategy. When it comes to social strategy use, the first-year students employed the highest degree of social strategies $\left(\mathrm{M}_{\text {first year }}=3.21\right)$. In contrast, the second-year students employed the least amount of social strategy $(M=2.91)$. With regard to the two subcategories of strategy use questionnaire, first- and second-year students used social strategies more frequently than affective strategies. On the other hand, third- and fourth-year students employed affective strategies more than social strategies. The most frequently used category was social strategy used by the first-year students $(M=3.21)$, and the least frequently used one was found to be affective strategies employed by second-year students $(M=2.82)$. In general, third-year students reported higher socio-affective strategy use $(M=$ 3.15) than others did.

\subsection{Relationship between EFL learners' self-efficacy and their years of study (The first research question)}

The purpose of the first research question was to examine the relationship between EFL learners' self-efficacy beliefs and their years of study. Students' years of study was categorized into four levels (first, second, third, and fourth year) that was considered as nominal data. Then, the students responded to each item of the self-efficacy questionnaire using a scale ranged from 0 to 100 points $(0=$ definitely cannot do it, $30=$ probably cannot do it, $50=$ maybe, $70=$ probably can do it, and $100=$ definitely can do it) to examine their perceived capabilities in a given task. The higher scores on this scale reflected more positive self-efficacy for learning beliefs. Afterwards, the self-efficacy score was converted into semi-interval data. Subsequently, a Chi-square test was run to examine the possible relationship between the two variables (self-efficacy and years of study).

\section{Table 2}

Chi-Square tests for the relationship between self-efficacy and years of study

\begin{tabular}{lccc}
\hline & Value & Df & Asymp. Sig. (2-sided) \\
\hline Pearson Chi-Square & 215.61 & 231 & .758 \\
N of Valid Cases & 170 & & \\
\hline
\end{tabular}

The two-sided asymptotic significance of the Chi-square statistic (.758) was higher than significance value (.05); it could be concluded that the relationship between these two variables was simply due to chance variation. This implied that each participant at specific year of study did not disclose different degrees of self-efficacy $(\chi 2=215.61, p>.05)$. Furthermore, the strength and direction of this insignificant relationship was examined by running Eta test, the results of which are presented in the following table:

\section{Table 3}

Directional measures for the relationship between self-efficacy and years of study

\begin{tabular}{llll}
\hline & & & Value \\
\hline Nominal by Interval & Eta & Self-efficacy Dependent & .208 \\
& & Years of study Dependent & .628 \\
\hline
\end{tabular}

Table 3 illustrated a low-level positive correlation between years of study and self-efficacy beliefs of students $(r=.208, p \geq .05)$. Salkind's (2010, p. 129) guidance was used for interpreting the ( $r$ ) value: 
Mojtabaee Hosseini, S. M., Tahriri, A., \& Danaye Tous, M.

\section{Table 4}

Guidelines for interpreting (r) value (adopted from Salkind, 2010)

\begin{tabular}{cl}
\hline r value & \multicolumn{1}{c}{ Interpretation } \\
\hline $0.8-1.0$ & very strong relationship \\
$0.6-0.79$ & strong relationship \\
$0.4-0.59$ & moderate relationship \\
$0.2-0.39$ & weak relationship \\
$0.0-0.19$ & very weak or no relationship \\
\hline
\end{tabular}

Based on the guidelines proposed by Salkind (2010), the self-efficacy of the students had weak relationship with their year of study and consequently it was not significantly associated with it. Thus, the first null hypothesis is retained implying that there were not statistically significant relationships between EFL learners' self-efficacy and their years of study.

\subsection{Relationship between EFL learners' use of social-affective strategies and their years of study (The second research question)}

The second research question was proposed to examine the possible relationship between Iranian EFL learners' social-affective strategy use and their years of study. A Chi-square test examined the possible relationship between the two variables (strategy use and years of study).

\section{Table 5}

Chi-Square tests for the relationship between strategy use and years of study

\begin{tabular}{lccc}
\hline & Value & df & Asymp. Sig. (2-sided) \\
\hline Pearson Chi-Square (affective strategies) & 80.751 & 63 & .065 \\
Pearson Chi-Square (social strategies) & 79.721 & 69 & .177 \\
Pearson Chi-Square (social-affective strategies) & 96.378 & 105 & .714 \\
N of Valid Cases & 170 & & \\
\hline
\end{tabular}

Neither affective strategy use nor social strategy use was found to be significantly correlated with years of study $\left(\chi^{2}\right.$ affective strategy use $=80.75, p>.05 ; \chi^{2}$ social strategy use $\left.=79.72, p>.05\right)$. Moreover, total social-affective strategy use was not found to be significantly associated with years of study ( $\chi 2$ social-affective strategy use $=96.37, p$ $>$.05). Therefore, the second null hypothesis was retained, too.

\section{Table 6}

Directional measures for the relationship between strategy use and years of study

\begin{tabular}{llll}
\hline & & & Value \\
\hline Nominal by Interval & Eta & Affective strategies Dependent & .231 \\
Nominal by Interval & Eta & Social strategies Dependent & .155 \\
Nominal by Interval & Eta & Social-affective strategies Dependent & .169 \\
\hline
\end{tabular}

In general, the degree of relationship between social-affective strategy use and EFL learners' self-efficacy was very weak $(r=.169)$. Referring to the guidelines proposed by Salkind (2010), the low $(r=.231)$ value for the affective strategies and years of study could be explained as the self-efficacy of the students had weak relationship with their affective strategy use and was not significantly associated with it. Moreover, the employed social strategies had very weak or no relationship with their year study and was not significantly correlated with it.

\subsection{Relationship between EFL learners' self-efficacy and their use of social-affective strategies across years of study (The third research question)}

To provide an answer to the third research question, Spearman rank-order correlation was run to determine 
The relationship between EFL learners' self-efficacy and their social-affective strategy use across years of study the possible relationship and the direction of the relationship between EFL learners' self-efficacy and their use of social-affective strategies across years of study.

\section{Table 7}

Spearman correlation for the relationship between self-efficacy and social-affective strategy

\begin{tabular}{lllc}
\hline Years of study & & social-affective strategies \\
\hline First year & Self-efficacy & Correlation Coefficient & .088 \\
& & Sig. (2-tailed) & .521 \\
& $\mathrm{~N}$ & 55 \\
\cline { 2 - 3 } Second year & Celf-efficacy & Correlation Coefficient & .001 \\
& & Sig. (2-tailed) & .995 \\
Third year & $\mathrm{N}$ & 40 \\
\cline { 2 - 3 } & Self-efficacy & Correlation Coefficient & $.435^{* *}$ \\
& & Sig. (2-tailed) & .007 \\
Fourth year & $\mathrm{N}$ & 37 \\
\cline { 2 - 3 } & Self-efficacy & Correlation Coefficient & $.434^{* *}$ \\
& & Sig. (2-tailed) & .007 \\
& & $\mathrm{~N}$ & 38 \\
\hline
\end{tabular}

Note. ${ }^{* *}$. Correlation is significant at the .01 level (2-tailed).

For the first- and second-year students, no significant relationship was found between self-efficacy and social-affective strategy use $(p \geq .05)$. However, for the third-year students, self-efficacy was found to be significantly and positively correlated with social-affective strategy use (Rho $=.435, p<.001$ ). Similarly, for the fourth-year students, self-efficacy was found to be significantly and positively correlated with social-affective strategy use $($ Rho $=.434, p<.001)$. This revealed that third- and fourth-year students with a higher level of self-efficacy tended to use social-affective strategies more frequently. The findings of this section partially rejected the third null hypothesis implying that there is a statistically significant relationship between third- and fourth-year EFL learners' self-efficacy and their use of social-affective strategies across years of study.

Fisher r-to-z transformation was used to calculate a value of $\mathrm{z}$ that was applied to assess the significance of the difference between the correlation coefficients in four independent samples.

\section{Table 8}

The results of Fisher r-to-z transformation

\begin{tabular}{lcc}
\hline \multicolumn{1}{c}{ Samples } & Z value & Sig \\
\hline First year students \& second year students & .41 & .68 \\
First year students \& third year students & -1.71 & .04 \\
First year students \& fourth year students & -1.71 & .04 \\
Second year students \& third year students & -1.96 & .02 \\
Second year students \& fourth year students & -1.97 & .02 \\
Third year students \& fourth year students & .01 & .49 \\
\hline
\end{tabular}

For the comparison between "first-year students \& second-year students" in terms of the degree of correlation between self-efficacy and social affective strategy use, rho first year students was greater than rho second year students, resulting that the value of $\mathrm{z}$ had a positive sign. However, for the comparison between "first-year students \& third-year students", rho first year students was smaller than rho third year students, resulting that the value of $z$ had a negative sign. This was also the case for the degree of correlation between self-efficacy and social-affective strategy use of "first-year students \& fourth-year students" as well as "second-year students \& fourth-year students." The $\mathrm{z}$ value for the comparison between the correlational values of "third-year students \& fourth-year students" was also positive because the correlation between self-efficacy and social-affective strategy use for the third-year student was relatively higher than that of the fourth-year students.

When it comes to the sig. value, the results showed that the difference between "first-year students \& 
second-year students" as well as "third-year students \& fourth-year students" with respect to their extent of correlation between self-efficacy and social-affective strategy use was not statistically significant. In contrast, the degree of correlation between self-efficacy and social-affective strategy use for "first-year students \& third-year students", "first-year students \& fourth-year students", "second-year students \& third-year students", and "second-year students \& fourth-year students" were found to be statistically significant.

\section{Discussion}

Regarding the first research question, no significant relationship between students' self-efficacy and their year of study was found. As a result, the first null hypothesis could not be rejected. The result was not congruent with that of Bonyadi, Rimani Nikou, and Shahbaz (2012) who found a positive relationship between self-efficacy of students and their year of study. According to them, learners who had studied English for a longer period of time, as it was mentioned to be more than three years in their paper, had higher mean scores in self-efficacy scale. This lack of relationship can be related to their home environment and lack of their parent attention to their children's self-efficacy. Conversely, students might have previous experience of learning English and because of that, year of study might not affect their self-efficacy to a significant extent.

Concerning the second research question, it was found that there was no significant relationship between social-affective use of students and their year of study. The second hypothesis was retained, too. This finding is again in contradiction with that of Bonyadi, Rimani Nikou, and Shahbaz (2012) who found a significant positive correlation between strategy use and students' years of English study. It was also not similar to Oxford and Nyikos' (1989) and Ramirez' (1986) findings which indicated that students with more years of language study, use language learning strategies more than less experienced students. The contradictory results may be due to other influential factors on students' use of strategies like their educational and cultural background, learning style and the atmosphere of the classroom. In case of social strategies, it may be due to the lack of teachers' attention and also lack of opportunity to use these strategies.

Regarding the third research question, it was found that for the first- and second-year students, the relationship between self-efficacy and social affective strategy use was not significant whereas a significant relationship was found between self-efficacy and social-affective strategy use for third- and fourth-year students. As a result, the third hypothesis was partially rejected. This finding contradicts with that of of Bonyadi, Rimani Nikou, and Shahbaz (2012) who concluded that there was no relationship between self-efficacy and language learning strategy use of students. It is partially in accordance with Purdie and Oliver' (1999) study which found that there is a high correlation between students' efficacy beliefs in various areas (e.g. speaking, listening, writing, and in general), attitudes to English, and language learning strategies. The result is also partly in line with the finding of Zarei and Gilanian's (2015) study which showed that there was a positive relationship between affective and memory strategies and general self-efficacy. However, it contradicts with Yilmaz's (2010) finding which revealed a low correlation between affective strategies and self-efficacy. She concluded that social, affective and memory strategies are the least used frequently strategies by students and need to be focused in language classrooms. The result is also in line with the findings of Magogwe and Oliver, (2007), Yang (1999), and Ghavamnia, Kassaian, and Dabaghi (2011) who reported a positive relationship between self-efficacy and language learning strategy use.

Part of the finding of this study is about students' degree of strategy use which showed that social strategy was the most frequently used $(M=3.21)$, and affective strategies was the least frequently used strategies among the participants $(M=2.82)$. This finding provides partial support to Yilmaz's (2010) finding indicating affective strategies as the least frequent one used by the learners.

\section{Conclusion and Implications}

The present study sought to investigate the relationship between self-efficacy and social-affective strategy 
use across years of study. It was found that neither self-efficacy nor social-affective strategy had a significant relationship with years of study. Moreover, the findings indicated that there was no relationship between self-efficacy and social-affective strategy use regarding first and second years of study. However, it revealed that there was a positive relationship between self-efficacy and social-affective strategy use across third and fourth years of study.

The findings of this study can benefit teachers in language learning classes as to treat each student considering their self-belief in their abilities. Teachers should know that first-year students with low degree of English knowledge require ways of improving their self-efficacy belief and due to the positive relationship which was found between self-efficacy and language learning strategies across third and fourth years of study, students' year of study should be taken into account. For this purpose, SILL and SELF-A can be used to give students a chance to focus their attention on the area in which they do not have enough confidence. These two instruments can also show the teachers and students which strategies are used less frequently and plan a way to expand the range of strategies used by them. They should motivate them to exert more effort in tasks and find the most appropriate strategies for every specific situation to experience success. Teachers should also be aware of their own role and students' peer role in improving learners' belief and know enough about sources and ways of developing self-efficacy. They should control their behavior in class and overcome their negative feelings and try to transfer positive belief to their students. In addition, they should prevent the negative influence of students on their peers. The result of this study also shows that, besides other factors influencing choice of strategies, self-efficacy should be considered.

The result of this study also benefits curriculum designers and material developers. These findings expand their view in providing materials for students. Using the results of empirical research, they will know what strategies should be highlighted more in English textbooks and what kinds of tasks and in what order should be set to improve self-efficacy and strategy use according to students' year of study. In addition, material developers and teachers should give more attention to the improvement of affective strategies in the textbooks and in the process of teaching and learning.

\section{References}

Bandura, A. (1977). Self-efficacy: Toward a unifying theory of behavior change. Psychological Review, 84, 191-215. http://dx.doi.org/10.1037/0033-295X.84.2.191

Bandura, A. (1986). Social foundations of thought and action: A social cognitive theory. Englewood Cliffs, NJ: Prentice Hall.

Bandura, A. (1989). Human agency in social cognitive theory. American Psychologist, 44, 1175-1184. http://dx.doi.org/10.1037/0003-066X.44.9.1175

Bandura, A. (1994). Self-efficacy. In V. S. Ramachaudran (Ed.), Encyclopedia of human behavior (Vol. 4, pp. 71-81). New York: Academic Press.

Bandura, A. (1997). Self-efficacy: The exercise of control. New York: W. H. Freeman and Company.

Bandura, A., \& Schunk, D. H. (1981). Cultivating competence, self-efficacy, and intrinsic interest through proximal self-motivation. Journal of Personality and Social Psychology, 41, 586-598. http://dx.doi.org/10.1037/0022-3514.41.3.586

Bonyadi, A., Rimani Nikou, F., \& Shahbaz, S. (2012). The relationship between EFL learners' self-efficacy beliefs and their language learning strategy use. English Language Teaching, 5(8), 113-121. http://dx.doi.org/10.5539/elt.v5n8p113

Crain, W. (2000). Theories of development: Concepts and applications (4 ${ }^{\text {th }}$ ed.). London: Prentice-Hall.

Datu, J. A. (2013). Be happy and believe in your capacity: Establishing link between subjective well-being and self-efficacy among Filipino adolescents. International Journal of Research Studies in Psychology, 2(3), 3-10. http://dx.doi.org/10.5861/ijrsp.2012.206

Demirel, M. (2009). The validity and reliability study of Turkish version of strategy inventory for language learners. World Applied Science Journal, 7(6), 708-714. 
Mojtabaee Hosseini, S. M., Tahriri, A., \& Danaye Tous, M.

Ghavamnia, M., Kassaian, Z., \& Dabaghi, A. (2011). The relationship between language learning strategies, language learning beliefs, motivation, and proficiency: A study of EFL learners in Iran. Journal of Language Teaching and Research, 2(5), 1156-1161. http://dx.doi.org/10.4304/jltr.2.5.1156-1161

Goulão, F. (2014). The relationship between self-efficacy and academic achievement in adults' learners. Athens Journal of Education, 1(3), 237-246.

Locke, E. A., \& Latham, G. P. (1990). Work motivation and satisfaction: Light at the end of the tunnel. Psychological Science, 1, 240-246. http://dx.doi.org/10.1111/j.1467-9280.1990.tb00207.x

Magogwe, J. M., \& Oliver, R. (2007). The relationship between language learning strategies, proficiency, age and self-efficacy beliefs: A study of language learners in Botswana. System, 35, 338-352. http://dx.doi.org/10.1016/j.system.2007.01.003

Mohammadi, H., \& Alizadeh, Kh. (2014). An investigation of reliability and validity of strategy inventory for language learning among Iranian university students. International Journal of English Language Teaching, 1, 53-63. http://dx.doi.org/10.5430/ijelt.v1n2p53

O'Malley, J. M., Chamot, A. U., Stewner-Manzanares, G., Kupper, L. J., \& Russo, R. P. (1985). Learning strategies used by beginning and intermediate ESL students. Language Learning, 35(1), 21-46. http://dx.doi.org/10.1111/j.1467-1770.1985.tb01013.x

Oxford, R. (1990). Language learning strategies. What every teacher should know. New York: Newbury House.

Oxford, R. L., \& Burry-Stock, Judith A. (1995). Assessing the use of language learning strategies worldwide with the ESL/EFL version of the strategy inventory for language learning (SILL). University of Alabama, Tuscaloosa, AL, USA. http://dx.doi.org/10.1016/0346-251x(94)00047-a

Oxford, R. L., \& Nyikos, M. (1989). Variables affecting choice of language learning strategies by university students. The Modern Language Journal, 73, 291-300. http://dx.doi.org/10.1111/j.1540-4781.1989.tb06367.x

Pajares, F. (2002). Overview of social cognitive theory and of self-efficacy. Retrieved from https://www.uky.edu/eushe2/Pajares/eff.html

Pajares, F., \& Kranzler, J. (1995). Self-efficacy beliefs and general mental ability in mathematical problem-solving. Contemporary Educational Psychology, 20, 426-443. http://dx.doi.org/10.1006/ceps.1995.1029

Purdie, N., \& Oliver, R. (1999). Language learning strategies used by bilingual school-aged children. System, 27(3), 375-388. http://dx.doi.org/10.1016/S0346-251X(99)00032-9

Ramirez, A. G. (1986). Language learning strategies used by adolescents studying French in New York schools. Foreign Language Annals, 19, 131-141. http://dx.doi.org/10.1111/j.1944-9720.1986.tb03108.x

Salkind, N. J. (2010). Statistics for people who (think they) hate statistics: EXCEL 2007 (2nd ed.). Thousand Oaks, CA: Sage.

Schunk, D. H. (1981). Modeling and attributional effects on children's achievement: A self-efficacy analysis. Journal of Educational Psychology, 73, 93-105. http://dx.doi.org/10.1037/0022-0663.73.1.93

Schunk, D. H., \& Gunn, T. P. (1986). Self-efficacy and skill development: Influence of task strategies and attributions. Journal of Educational Research, 79, 238-244. http://dx.doi.org/10.1080/00220671.1986.10885684

Schwarzer, R. (Ed.). (1992). Self-efficacy: Thought control of action. Washington, DC: Hemisphere.

Tenaw, Y. (2013). Relationship between self-efficacy, academic achievement and gender in analytical chemistry at Debre Markos college of teacher education. African Journal of Chemical Education, 3(1), 3-28.

Wood, R., \& Bandura, A. (1989). Social cognitive theory of organizational management. Academy of Management Review, 14(3), 361-384.

Yang, N. (1999). The relationship between EFL learners' beliefs and learning strategy use. System, 27(4), 515-535. http://dx.doi.org/10.1016/S0346-251X(99)00048-2

Yilmaz, C. (2010). The relationship between language learning strategies, gender, proficiency and self-efficacy beliefs: A study of ELT learners in Turkey. Procedia Social and Behavioral Sciences, 2, 682-687. http://dx.doi.org/10.1016/j.sbspro.2010.03.084

Zajacova, A., Lynch, S. M., \& Espenshade, Th. (2005). Self-efficacy, stress, and academic success in college. 
The relationship between EFL learners' self-efficacy and their social-affective strategy use across years of study Research in Higher Education, 46(6), 677-706. http://dx.doi.org/10.1007/s11162-004-4139-z

Zarei, A., \& Gilanian, M. (2015). Self-efficacy as a function of language learning strategy use. British Journal of Education, Society \& Behavioural Science, 9(3), 223-235. http://dx.doi.org/10.9734/BJESBS/2015/18735

Zimmerman, B. J. (2000). An essential motive to learn. Contemporary Educational Psychology, 25(1), 82-91. http://dx.doi.org/10.1006/ceps.1999.1016

Zimmerman, B. J., Bandura, A., \& Martinez-Pons, M. (1992). Self-motivation for academic attainment: The role of self-efficacy beliefs and personal goal-setting. American Educational Research Journal, 29, 663-676. http://dx.doi.org/10.3102/00028312029003663

Zimmerman, B., \& Kitsantas, A. (2007). Reliability and validity of Self-Efficacy for Learning Form (SELF) scores of college students. Journal of Psychology, 215(3), 157-163.

http://dx.doi.org/10.1027/0044-3409.215.3.157 
Mojtabaee Hosseini, S. M., Tahriri, A., \& Danaye Tous, M. 